\title{
'Wrongful life' lawsuits for faulty genetic counselling: should the impaired newborn be entitled to sue?
}

Amos Shapira Tel Aviv University, Tel Aviv, Israel

\begin{abstract}
$A$ "wrongful life" suit is based on the purported tortious liability of a genetic counsellor towards an infant with hereditary defects, with the latter asserting that he or she would not have been born at all if not for the counsellor's negligence. This negligence allegedly lies in the failure on the part of the defendant adequately to advise the parents or to conduct properly the relevant testing and thereby prevent the child's conception or birth (where unimpaired life was not possible).

This paper will offer support for the thesis that it would be both feasible and desirable to endorse "wrongful life" compensation actions. The genetic counsellor owed a duty of due professional care to the impaired newborn who now claims that but for the counsellor's negligence, he or she would not have been born at all. The plaintiff's defective life (where healthy life was never an option) constitutes a compensable injury. A sufficient causal link may exist between the plaintiff's injury and the defendant's breach of duty of due professional care and an appropriate measure of damages can be allocated to the disabled newborn. Sanctioning a "wrongful life" cause of action does not necessarily entail abandoning valuable constraints with regard to abortion and euthanasia. Nor does it inevitably lead to an uncontrolled slide down a "slippery slope".
\end{abstract}

(Fournal of Medical Ethics 1998;24:369-375)

Keywords: Bioethics; wrongful life; genetic counselling; impaired newborn

\section{The problem}

Consider the following case: prior to her marriage, a woman consulted with a genetic counsellor as to the chances of a certain hereditary defect (Hunter's Disease) that exists in her family impairing her future offspring. If this were to be the case, she was determined not to have any male children. The genetic consultant, due to his (alleged) negligence in the testing and counselling processes, concluded that no such risk existed, and, on the basis of this advice, the woman became pregnant and bore a son. However, the infant was in fact afflicted with the disease, which severely handicapped his physical and psychological development. Consequently, the newborn brought a personal injury suit for "wrongful life" against the consultant. ${ }^{2}$ A "wrongful life" suit is based on the purported civil liability of a genetic counsellor towards an infant with hereditary defects, with the latter asserting that he or she would not have been born at all if not for the counsellor's negligence. This negligence allegedly lies in the failure on the part of the defendant adequately to advise the parents or properly to conduct the relevant testing and thereby prevent the child's conception or birth (where unimpaired life was not possible).

This essay will present support for the thesis that it would be both feasible and desirable to endorse a "wrongful life" compensation action brought by a handicapped newborn against the negligent genetic counsellor. I shall argue that the genetic counsellor owed a duty of due professional care to the impaired newborn who now claims that but for the counsellor's negligence, he or she would not have been born at all and that the plaintiff's defective life (where healthy life was never an option) constitutes a compensable injury. Moreover, I shall maintain that a sufficient causal link may exist between the plaintiff's injury and the defendant's breach of duty of due professional care and that an appropriate measure of damages can be allocated to the disabled newborn. I shall further assert that sanctioning a "wrongful life" cause of action does not necessarily entail or import abandoning valuable constraints with regard to abortion and euthanasia. Nor does it inevitably lead to an uncontrolled slide down a "slippery slope" towards the wholesale categorisation of a host of impairments as compensable injuries and towards burdening parents with sweeping responsibility to protect future offspring from illness or suffering by avoiding conception or birth.

\section{Duty of due care}

Does a genetic counsellor owe a duty of due care to a newborn plaintiff when the former's alleged 
professional negligence predates the latter's birth or even conception? The answer, in principle, should be in the affirmative. In acting with reasonable professional skill and prudence, a genetic counsellor enables parents to avoid the conception or carrying to term of a defective fetus by adequately apprising them of the risks involved. If a genetic counsellor fails adequately to perform this duty, he or she may be regarded as professionally negligent under customary malpractice tort standards.

\section{Appropriate scope}

The type of professional conduct that should or should not be considered negligence will not be discussed here. What is the appropriate scope of the duty of professional due care owed by a genetic counsellor to a newborn in the context of a "wrongful life" lawsuit? What are the normative yardsticks for measuring the exercise of proper professional skills in genetic diagnosis and therapy? The answer to these questions depends, amongst other things, on a public policy determination as to the appropriate range of genetic testing and counselling services offered to the public. Such a decision, in turn, will be affected by a variety of scientific and socio-moral, risk-benefit calculations. Difficult societal choices will have to be made in this respect, in light of the continuing progress in mapping the human genome, the expansion of available preconception and prenatal diagnostic and therapeutic capabilities, and the complex considerations regarding accessibility of genetic testing, counselling and therapy services and their overall societal implications. In balancing all of these different, sometimes contending, concerns, one must be alert to the risk of excessively "defensive" medicine with its negative consequences. Clearly, not in every case is failed therapy, defective testing, flawed diagnosis or misguided counselling tantamount to professional negligence. Usually, a genetic counsellor will meet his or her professional obligation simply by duly informing potential parents regarding the extent and likelihood of the risks involved, leaving the ultimate decision in their hands. The professional advice provided must be reasonable under the circumstances and must correspond to available contemporary scientific knowledge.

Obviously, the recipients of the information are the potential parents; they are the actual participants in the dialogue with the genetic counsellor. But the ultimate beneficiary of this process is the child. A counsellor's duty of due care is owed to the child, despite the fact that this duty can only be fulfilled in the framework of the geneticist's contact with the child's surrogates, ie, the prospective parents. It is the child's interest that $i$. protected by obligating a genetic counsellor to act with reasonable professional skill and prudences Such is the nature of this situation that the child' interest can only be promoted at the relevant time by the potential parents through their informe of decision whether or not to conceive or carry t $\Theta$ term. Still, conceptually, it is the newborn's indeês pendent right that is at stake. To be sure, people' $\vec{E}$ decisions regarding conception and birth are motivated by a myriad of considerations, includw ing personal whims and egocentric calculation $\frac{5}{3}$ But there is no reason to assume that in makin such decisions, potential parents are inclined t $\stackrel{\leftrightarrow}{\leftrightarrow}$ ignore the individual interests of their futures offspring. Prospective parents who are informew that their unborn child is likely to be severelyb handicapped and, consequently, decide not to conceive, or to abort, may indeed be so motivated by self-regarding worries for their own awful situ命 ation should their child be born into such a devas tating condition. Yet it is amply sensible to assum that a choice not to conceive, or a decision to abort, in such circumstances stems primarily fronde a genuine concern for the welfare of their poten offspring. Most prospective parents are likelyate opt for not burdening their would-be child with an awful existence, intuitively believing tha⿳亠 such a devastated life would be worse than no life at all. A geneticist's failure duly to inforn $\$$ potential parents in their capacity as surrogate $\overrightarrow{\vec{E}}$ may, therefore, provide the basis for an individua "wrongful life" claim brought by a handicappef newborn. Parents may have a separate claim of their own, known as a "wrongful birth" action against a negligent consultant, in which they seef compensation for the damage they suffered as result of the birth of their disabled child. This dis tinct cause of action will not be discussed in this essay.

\section{Public health interests}

There is no inherent injustice in holding genetio counsellors liable towards an impaired newborn for professional misconduct, ie, behaviour that under the circumstances, falls short of ordinarily required standards of due care. Awareness on the part of professionals that their professions performance is subject to such normative stand ards of behaviour is likely to prompt them to act with skill and caution and, thereby, reduce the incidence of professional malpractice. This woul certainly conform with the deterrence an $\&$ prevention policy-goal of tort law. Moreove? widespread public awareness regarding the ace countability of genetic counsellors for negligent 
professional behaviour will likely be accompanied by an overall increase in the resort to genetic counselling; this would advance public health interests by curbing the incidence rate of genetic disorders.

An additional argument in support of imposing a legal duty of professional due care upon genetic counsellors emanates from the "damagespreading" policy-goal of negligence law. Health care organisations and professionals are generally considered to be more efficient "damagespreaders" than individual patients. The former are in a position that allows them to insure themselves against professional liability and then spread the premium costs to the general public through a health-delivery insurance plan. This would be preferable to burdening the individual families (or some welfare agency) with the enormous costs involved in dealing with a genetic disease.

There are those who would prefer a social security solution to providing for the needs of impaired newborns. According to this view, the state should support handicapped children and ensure their welfare as part of a general social policy to support the needy out of the public purse. Proponents of such a public welfare policy are likely to question the suitability of a private lawsuit brought against an allegedly negligent physician as a means to guarantee the care and services required by disabled infants. They are likely to be skeptical as to whether such an implement has the potential to fulfil the widely hailed policy goals of deterrence, prevention and efficient and fair spreading of the damage. A general welfare solution would, of course, require public funding and special enabling legislation. Such a solution would be conditional upon community empathy for and solidarity with the needy and a general commitment to providing them with a fair level of subsistence. It would be contingent upon the existence of a socioeconomic ethos and the political culture of a welfare state that recognises the entitlement of its needy to public support. However, the question arises as to whether such socio-political requirements are compatible with current privatisation and market-economy trends. In any event, my assumption in this essay is that, in the absence of such a pervasive welfare support system, the only possibility open to an impaired newborn seeking proper - or more than basic - redress would be to bring a tort law action against a professionally negligent genetic counsellor.

Finally, it would seem that basic precepts instincts, if you wish - of justice and fairness lend further support to holding negligent professionals responsible for the consequences of their substandard, tortious conduct. A wrongdoer should not be allowed to escape liability towards the victim of his or her malpractice. Where injury can be linked to some negligent behaviour, the tortfeasor should bear the responsibility of compensating the injured party.

\section{Redressable injury}

The thorniest, most perplexing dilemmas relating to "wrongful life" lawsuits arise in the context of morality and logic. Under the principles of tort law, only a breach of a duty of due care, which renders a legally recognised injury, will provide the injured party with a cause of action to sue the wrongdoer for compensation. Should the condition of impaired life (in a situation where healthy life was never an option) be regarded as a compensable damage? Even on the assumption that the genetic counsellor did act negligently when conducting testing or providing information to the would-be parents, should a newborn be permitted to claim that the defective life forced upon him or her constitutes a harm for which he or she deserves to be redressed?

1. MORAL MISGIVINGS: THE IMPACT ON ABORTION AND EUTHANASIA

There are those who maintain that endorsement of the above claim is tantamount to a normative affirmation that non-life is preferable to a life afflicted with disease. And, they further assert, such affirmation reflects an expectation of indeed, a claim to - products of procreation that do not fall short of perfection. Moreover, this endorsement allegedly constitutes a direct challenge to the cherished tenet of the sanctity of life according to which existence, even defective existence, is always preferable to non-existence - and is bound to legitimise and promote both abortion and euthanasia.

On the subject of abortion, it is interesting to note that under Israeli law, the interruption of pregnancy is authorised in a situation where "the child is likely to have a physical or mental defect". It would appear that the phraseology adopted by the legislature reveals an unmistakably lenient policy vis-à-vis abortion for eugenic reasons: a physical or mental defect does not need to be extensive or grievous in order to justify interruption of a pregnancy; an ordinary, perhaps even relatively minor defect seems to be sufficient. Furthermore, the defect need only be "likely," not certain or probable. The term "likely" seems to signify a mere reasonable possibility, which may fall short of near certainty or high probability. The 
possible risk of such a defect can stem from a variety of causes, including a known family history of genetic defective traits with a likely hereditary effect.

A permissive stand, de jure as well as de facto, on abortion for eugenic reasons actually provides a solid foundation for an impaired newborn's claim that had it not been for the genetic counsellor's negligence, his or her parents might have indeed opted for legal abortion. It is quite reasonable to assume that most people would choose not to conceive and many would prefer to abort, if forewarned that their child - if born - would be afflicted with a terrible disease such as, for instance, Tay-Sachs. The faulty genetic counselling deprived the parents of their legally recognised option to abort a defective fetus. Thus, legal recognition of a cause of action for "wrongful life" corresponds conceptually to the legal endorsement of the parental authority to refrain from conceiving or giving birth to an impaired child. Moreover, if recognition of eugenic grounds for abortion is the manifestation of a general goal to protect the fetal - and not only the maternal - interest (ie, if a defective fetus possesses a "personal" right to be aborted), then denial of that right through faulty prenatal genetic counselling may amount to "informed consent" based negligence. In other words, the claim of an impaired infant plaintiff (a former defective fetus) is that had he or she not received negligent advice (by proxy - the parents), he or she would have exercised his or her legal right to choose not to be born into a defective state. Now the infant has no choice but to lead an impaired existence and, for that, he or she seeks to be redressed.

Legal sanctioning of a "wrongful life" cause of action can also be examined in the context of the "right to die" debate. One could argue that recognition of impaired life as a compensable harm (when healthy life was never an option) undermines the traditional tenet of the sanctity of human life and blatantly devalues the social worth of the handicapped. Such an approach may even foster dangerous termination-of-life decisions regarding the elderly and the ailing, ranging from withholding or withdrawing life-support to all-out assisted suicide and active euthanasia.

A comprehensive discussion of the intricacies of the death and dying issue - underlying values, policy goals, decision-making mechanisms - falls beyond the ambit of this essay. Suffice it to say that compensating a handicapped newborn for a negligent, preconception genetic diagnosis hardly implies that the disabled life of the infant plaintiff is devoid of all worth; it is precisely because the plaintiff's handicapped life does deserve respect and compassion that he or she ought to be offere pecuniary redress that is geared to ensure decent, if hampered, existence. Decisions regardঙ्ञ ing artificial prolongation of the dwindlingo agony-filled life of a terminally-ill patient entail different matrix of values and concerns and raises issues that are quite distinct from those involved in the matter of redressing an impaired infant foth faulty prenatal diagnosis when healthy life was never an available alternative. Indeed, administering deliberate and direct action to terminates life is hardly analogous to awarding pecuniary redress for hampered life. In other words, whilẹ the concern for the sanctity of life is clearls involved in the comparison of existing (iक burdened) life to the termination thereof, it i⿹ hardly a self-evident issue in the attempt to measure non-existence against impaired life. $A$ hypothetical preference not to have been born a $\vec{\xi}$ all over the misery of an awful life is one thing actually opting to terminate a life filled witl $\frac{\$}{5}$ agony is quite another. It might be that a permis sive stand on the "right to die" issue could indirectly facilitate endorsement of "wrongfuce life" negligence lawsuits; namely, if a certip

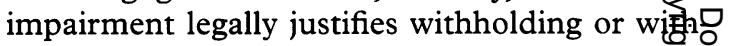
drawing life-sustaining treatment and possib even direct and deliberate termination of lifeo then one might surely surmise that such ais impairment is to be regarded as a compensable damage for the purposes of a tort action fo $\overrightarrow{\underline{E}}$ "wrongful life". But the logic of this syllogisn?

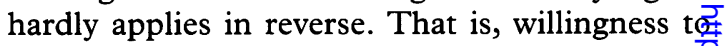
recognise actions for monetary compensation for. "wrongful life" does not necessarily imply a sanc tioning of various kinds of mercy killing. A legas system can be lenient towards disabled infant who wish to sue negligent genetic counsellors fog damages for "wrongful life," while simultane ously adopting a proscriptive stance on the "right to die" claim.

2. LOGICAL INTRICACIES: DEFECTIVE LIFE AS A COMPENSABLE HARM

As previously noted, a legally recognised injurs (resulting from a breach of a duty of due care) is precondition of liability for negligence, whic entitles the injured party to compensation. Casp one logically argue that the impaired state intథ which a child was born (when healthy life was never possible) constitutes a redressable harm After all, compensating a harmed plaintiff is ordi narily designed to restore the status quo before the injury, namely, to create - through propes compensation - conditions that are as close as possible to the pre-injury state. When a plaintiff 
asserts a preference for non-existence over hampered life, he or she is actually claiming that the damage suffered is equal to the gap between these two states. Is a court of law capable of making such an assessment? And which logical yardsticks should be employed?

According to a widely held opinion, there is, and can be, no logical foundation to a "wrongful life" claim. A state of non-existence is devoid of any moral status and legal consequence. It lacks any value and worth, it offers no basis for comparison with any form of existence, and it cannot constitute an object for any claim of right. Therefore, any attempt to evaluate the meaning of non-life as compared to that of defective life is a logical impossibility. Yet despite the undeniable force of this argument, two Israeli Supreme Court justices were not averse to comparing nonexistence to defective existence. ${ }^{2}$ They were prepared to decree that in certain situations (though admittedly rare and extreme), a "reasonable man" could conclude - even if intuitively - that a person would indeed be better served not being born at all rather than having a short and seriously impaired life filled with unremitting suffering. According to this view, the cause of action for "wrongful life" can and should be restricted to only exceptionally severe disabilities. Such a limitation would minimise the alleged affront to the moral value of the sanctity of human life as well as reduce the potential for a flood of "wrongful life" lawsuits. By the same token, this restriction would lower the cost of liability insurance for genetic counselling and treatment services. However, this judicial stance has a major difficulty: the inherent necessity to distinguish between truly severe handicaps (allowing a cause of action) and less-thanextraordinarily grave defects (not providing a right to sue). How would blindness, for instance, be classified? Or deafness? Or diabetes? Or Down's syndrome? Or being born missing a limb? The protagonists of this view failed to offer any classification of degrees of disability.

An alternative approach, preferred by two other justices of the Israeli Supreme Court in the above cited decision, deals with the logical dilemma of comparing non-life with defective life by side-stepping (or even leaping over) it. According to this approach, legal responsibility for "wrongful life" can be established without measuring non-life against impaired life and without endorsing a "right not to be born". Indeed, such a comparison is logically impossible, and a right to non-existence is inconceivable. Judges are incapable of gauging the meaning of non-life and of evaluating its worth in compari- son to hampered life. These justices view a physician's "wrongful life" liability towards a disabled infant as resting on the plaintiff's right to a life free of handicap. Accordingly, the responsibility of a negligent genetic expert is based not on the actual generating of life nor on the prevention of non-life, but, rather, on the creation of impaired life. Thus, the quantum of damage should be measured by comparing the actual impaired life of a plaintiff to a hypothetical unimpaired life, rather than by comparing defective life to non-existence. The compensation awarded for such damage is not intended to restore a plaintiff to the condition of non-life that would have existed were it not for the defendant's faulty behaviour but, rather, to redress the plaintiff for the impairment with which he or she was born.

In other words, the reality of the matter is that the handicapped infant exists. $\mathrm{He}$ or she is doomed to impairment, suffering, and to a needy existence due to the defendant's professional negligence. It is true that initially, the only alternative to disabled life was not to be born at all. But at the point at which a "wrongful life" suit is brought, this alternative no longer exists. Indeed, the infant is neither entitled to nor capable of being restored to the pre-injury state of non-existence. However, the impaired plaintiff did acquire a right to appropriate recompense by virtue of the defendant's malpractice. This negligence effected two simultaneous results: the child's actual birth and his or her inevitably handicapped condition. Though logically these two realities are unequivocally intertwined, a conceptual distinction can be made. The impaired child brings a suit for his or her handicapped condition, not for being brought into existence. The law can and should provide an impaired newborn with the right to be compensated by a negligent genetic counsellor for the damage inherent to his or her hopeless, agonydominated state as compared to healthy life.

One can still argue that the normal-life/ defective-life (rather than the non-life/defectivelife) comparison proposed by the latter two Israeli Supreme Court justices is flawed logically. This is because the existence itself and the defect inherent to it are inseparable. The life and impairment of a handicapped newborn are one consolidated entity. Moreover, the normal-life/defective-life comparison in the context of "wrongful life" actions is grounded in the presumption of a right to be born healthy. Anyone who denies such a claim of right must also reject the comparison for which it is the basis. Yet the normal-life/defectivelife comparison does present a construct that judges can understand and that allows for compensation based on a distinction familiar to 
the judiciary, that is, between the rule and the exception, the normal and the abnormal. The compensation sought is designed to redress the plaintiff for the diminution of his or her hypothetical healthy life. It is unnecessary - and improper - to reject a "wrongful life" claimant merely because he or she cannot be restored to the pre-injury, pre-life state. In so doing, we would effectively and unjustifiably be waiving a wrongdoer's liability and denying redress to a deserving victim. The inherent unfairness of such an outcome is all the more apparent in view of the relative ease with which courts in countries such as the US, England, and Germany have recognised the above mentioned "wrongful birth" cause of action, entitling the parents of a handicapped child to their damages from a negligent genetic counsellor even when unimpaired life was never possible for the child. Why, therefore, should the system discriminate against an impaired newborn and ignore his or her unique suffering and needs?

\section{The "slippery slope" trepidation}

I have shown that proper policy considerations do in fact support recognition of a "wrongful life" action. The final issue still to be confronted is whether such a cause of action, although in itself legitimate and even desirable, should none the less be rejected lest its endorsement have a snowball effect and result in unavoidable recognition for purportedly analogous though less or not-at-all deserving claims. For example, what about a newborn who seeks to sue a genetic consultant for alleged negligence in advising the claimant's parents that he or she would be tall with a fair complexion and blue eyes, while the genetic reality was that the infant could only be, as indeed he or she was, short with a dark complexion and brown eyes? And what if a child seeks compensation for "wrongful life" not from a genetic counsellor but from his or her parents, claiming that were it not for their parental imprudence, he or she would not have been born into a life burdened by any number of disadvantages genetic illness or HIV infection, the stigma of illegitimacy, religious persecution or ethnic prejudice, racial discrimination or socio-economic deprivation?t

A serious "slippery slope" argument should not be dismissed lightly. Still, the rather routine warning against an uncontrollable descent down a dangerous "slippery slope" is often unduly manipulated and abused in normative discourse. A "slippery slope" argument recognises the inherent acceptability or even desirability of the practice in question but none the less calls for its abandonment because of the alleged potential fot a snowball effect. But before being convinced be? such an argument, one must always consider the alternative to renouncing the practice under debate: to stand firm at the edge of the menacing slope and effectively to avoid the undesired dete $\frac{\bar{\sigma}}{\overline{6}}$ rioration. A judge should not ordinarily hesitate tહ hand down a decision considered justified in the्छ circumstances of the case-at-bar because of mere apprehension that it could be misapplied of improperly extended to future, misleadingly simi $\vec{\omega}$ lar cases. Legal reasoning draws on the juristies ability to analogise from and distinguish betweer comparable fact/law patterns.

Genetic impairments such as Hunter's Diseasêt clearly constitute compensable bodily damage్ల under the customary social conventions manifested in the principles of tort law. Acknowledg을 ment of this fact will not necessarily lead to recog $\bar{\square}$ nition of being born short with a dark complexior and brown eyes as a redressable harm. A cour upholding a "wrongful life" claim brought by, fo example, a Hunter's-afflicted child will hardly be compelled by ethics, logic, or social policy to trgate in a similar fashion a short, dark-complexioned; and brown-eyed newborn plaintiff. Likewe judicial affirmation of a "wrongful life" act against a geneticist will not inevitably result in endorsement of "wrongful life" suits lodged b妱 children against their parents. After all, a compen sation claim against a genetic counsellor for faulty professional conduct is firmly grounded in the traditional legal notion of negligence. There i nothing revolutionary in holding a physician liable for breach of a professional duty of due care Imposing upon parents a duty of due care to pre훙 vent the conception or birth of a child is a funda mentally different matter; such a duty would have to be predicated on a completely separate and new concept of a parental responsibility to spare potential offspring a life burdened by sickness encumbered by any type of social deprivation. A decision as to whether or not to concede such $\mathrm{N}$ parental legal duty to refrain from bringing intor life a Tay-Sachs, or HIV-positive, or illegitimate or religiously persecuted, or ethnically prejudicedo or racially-discriminated-against, or socio economically deprived child would depend on plethora of socio-moral values and policy consid $\stackrel{\oplus}{\rightarrow}$ erations, including the right of parents to privacyo and freedom of conscience and religion as well a\$ currently propagated claims for procreational lib $\frac{\rho}{\mathbb{Q}}$ erty and a right to parenthood. However, many o $\$$ these considerations are of little relevance to the firmly established and widely recognised general 
duty of professionals to treat their patients, clients, and customers with reasonable skill and prudence.

In conclusion, if on the basis of its merits, one is inclined to endorse a "wrongful life" compensation action initiated by a handicapped newborn against a negligent genetic counsellor, one need not be deterred by such speculative and highly irrelevant "slippery slope" apprehensions.

Amost Shapira MFur, MCL, FSD, is Professor of Law, former Dean, Faculty of Law, Tel Aviv University, Israel, Incumbent of the Lubowski Chair of Law and Biomedical Ethics, Faculty of Law, Tel Aviv University, and Director, Minerva Center for Human Rights, Tel Aviv University.

\section{References}

1 For an expanded version of this essay see: Shapira $A$. The human right not to be born impaired: issues of logic, value and policy. In: Immenga U et al, eds. Festschrift fur Ernst-foachim Mestmacker. Baden-Baden, Germany: Nomos, 1996: 293; and Shapira A. "Wrongful life" lawsuits for faulty genetic counselling: the impaired newborn as plaintiff. Tel Aviv University Studies in Law 1997;13:97-114.

2 CA 518, 540/82, Zeitzoff v Katz, [1986] 40(2) PD 85 (Supreme Court of Israel).

3 For a discussion supporting the view that the fundamental problems in dealing with the "wrongful life" concept relate to the physician's alleged duty to the fetus and the notion of life as a harm, see Botkin JR. The legal concept of wrongful life. fournal of the American Medical Association 1988;259:1541.

4 For a position favouring parental responsibility to avoid a "wrongful life", see Steinbock B, McClamrock R. When is birth unfair to the child? Hastings Center Report 1994;24:15. For a skeptical view as to parental obligations in this regard, see Dworkin RB.The new genetics. In: Childress JF et al, eds. Bio law (resource manual) 1986;1:89, 100-1.

\section{Correction}

Bioethics of the refusal of blood by fehovah's Witnesses: part 1. Should bioethical deliberation consider dissidents' views? There was a mistake in this paper by Dr Osamu Muramoto, which was published in the August issue of the journal. Dr Muramoto has written to the journal apologising for his mistake and asking that an erratum note be published.

The sentence containing the mistake was published thus: The governing body teaches that the "prohibited" blood components are "major", whereas acceptable components are "minor" or "small fractions", stating that the major components are limited to only those that pass through the placental barrier during pregnancy, and that on this basis a JW may accept them in good conscience.

It should have read (changed word in bold):The governing body teaches that the "prohibited" blood components are "major", whereas acceptable components are "minor" or "small fractions", stating that the minor components are limited to only those that pass through the placental barrier during pregnancy, and that on this basis a JW may accept them in good conscience. 